\title{
AS PLANTAS E A QUALIDADE DE VIDA HUMANA
}

Alfredo Pereira Junior

Professor Doutor do Departamento de Educação do Instituto de Biociências da UNESP - Campus de Botucatu, e docente no Programa de Pós Graduação em Filosofia da Faculdade de Filosofia e Ciências - UNESP - Campus de Marília. E-mail: alfredo.pereira@unesp.br

\section{RESUMO}

Para se avaliar o papel das plantas na qualidade de vida humana, é preciso entender os tipos de interação que ocorrem entre humanos e plantas, no processo perceptivo e na ação adaptativa. Uma explicação a respeito da negligência frente ao papel das plantas (a "cegueira botânica") pode ser encontrada no processo de evolução humana: com a emergência da linguagem verbal, tornando-se meio privilegiado de relação social, nossa interação com a natureza deixa de ser presencial (ou seja, deixa de ser uma presença, no sentido de Goethe), e passa a ser mediada por representações. Pode-se então identificar um "esquecimento do Ser" das plantas, no sentido de Heidegger; porém, este filósofo, embora próximo de Goethe, atribuía um papel central à linguagem (não a tecnocientífica, mas a poética) na manifestação do Ser. Tendo em vista que no sistema capitalista nossa interação com a natureza é balizada pelos valores de troca, e não por valores de uso (ou seja, uma efetiva qualidade de vida), propõe-se a construção de um novo modelo filosófico da interação Homem-Plantas, a ser estendido para as diversas ciências humanas, em particular para a Economia Política.

PALAVRAS-CHAVE: Plantas. Qualidade de Vida. Presença. Representação. Linguagem.

\section{PLANTS AND THE QUALITY OF HUMAN LIFE}

\begin{abstract}
In order to evaluate the role of plants in the quality of human life, it is necessary to understand the types of interaction that occur between humans and plants, in the perceptive process and in the adaptive action. An explanation of the neglect about the role of plants ("botanical blindness") can be found in the process of human evolution: with the emergence of verbal language, which
\end{abstract}


became a privileged means of social relation, our interaction with nature ceases to be a presence (in the sense of Goethe), and becomes mediated by representations. One can then identify a "forgetting of the Being" of plants, in Heidegger's sense; however, this philosopher, although close to Goethe, attributed a central role to language (not techno-scientific, but poetic) in the manifestation of Being. In view of the problems of human life generated by the capitalist system, in which our interaction with nature is marked by the values of exchange (and not by the values of use that contribute to an effective quality of life), it is proposed to construction of a new philosophical model of ManPlant interaction, to be extended to the various human sciences, in particular to Political Economy.

KEYWORDS: Plants. Quality of Life. Presence. Representation. Language.

\section{INTRODUÇÃO}

Considerando-se que a evolução humana se fez, em milhões de anos, em uma interação direta com as demais formas de vida (bactérias, arquea, plantas, fungos), seria possível para populações da espécie humana usufruir de qualidade de vida sem a interação direta com elas, em particular com as plantas? Será que uma existência em meio a computadores e brinquedos de plástico, aliada a uma alimentação com comida industrializada e/ou contaminada por aditivos químicos artificiais, e resíduos de defensivos agrícolas, pode ser saudável para uma criança? As questões acima, de natureza prática, demandam uma reflexão filosófica a respeito da importância das plantas para a qualidade de vida humana, e dos possíveis motivos que nos teriam levado a negligenciar as plantas como elo na evolução da vida terrestre que torna possível à própria existência dos animais, e como condição necessária para sua qualidade de vida.

Para avaliar o papel das plantas na qualidade de vida humana, é necessário entender os tipos de interação que ocorrem entre humanos e plantas, no processo perceptivo e na ação adaptativa. Uma explicação da negligência sobre o papel das plantas a "cegueira botânica", uma expressão introduzida por Wandersee e Schussler (2002) pode ser encontrada no processo da evolução humana: com o surgimento da linguagem verbal, que se tornou um meio privilegiado de relação social, nossa interação com a natureza deixa de ser presença (no sentido de Goethe), e torna-se mediada por representações.

A ciência moderna, a partir da física de Galileu e Newton, construiu-se em um paradigma filosófico (chamado de "Internalismo", na Filosofia da Mente) no qual as qualidades subjetivas passaram a ser consideradas intrínsecas à mente, o que subtrai o papel central das 
interações com as plantas para a geração de experiências qualitativas humanas. Entretanto, a suposta autonomia da mente para gerar suas experiências qualitativas parece ser ilusória; seria possível vivenciar uma experiência qualitativa de um excelente vinho, a partir do consumo de um vinho barato? A consideração das qualidades das plantas, e sua importância para a qualidade da vida humana, sugere a adoção de um paradigma filosófico Externalista em Filosofia da Mente, no qual as efetivas interações com o ambiente físico, biológico e social são consideradas como constitutivas do conteúdo de nossas experiências conscientes.

Ao se reconhecer a importância das plantas, pode-se conceber novas tecnologias que promovam maior proximidade, ao invés de nos afastar delas. Pode-se inclusive resolver problemas sociais, como o desemprego e o aumento de transtornos mentais, a partir de um novo modelo de relação homem-planta.

\section{MODALIDADES DE INTERAÇÃO HOMEM-PLANTA} plantas:

Destacamos três modalidades de interação entre populações da espécie humana e

1) Sensorial: As qualidades das plantas dão conteúdo a nossas experiências conscientes: sabores, odores, cores;

2) Nutricional: Por meio da fotossíntese, as plantas (autótrofas) produzem os compostos químicos que fornecem a energia útil para a vida animal (heterótrofa);

3) Econômica: As plantas fornecem diversos materiais e processos de interesse econômico, inclusive para geração de energia para o funcionamento de máquinas.

A interação sensorial pode ser abordada a partir de Aristóteles, considerado o "Pai da Biologia". Embora ele não tivesse explicitamente discutido esse tópico, podemos identificar sua concepção como implícita na abordagem empírica da natureza ("mundo sublunar”). Em Aristóteles, o sistema vivo se compõe de uma forma em atividade na matéria. A forma define sua espécie biológica, enquanto a matéria define sua individualidade. Há ainda a causa formal, pela qual a forma existente em um substrato material se transmite a outro substrato material. Deste modo, a apreensão das formas sensíveis da planta se faria por meio da causação formal, sendo contingente à nossa efetiva interação com elas.

Em Aristóteles, nossas experiências subjetivas não poderiam ser como são e sem a interação sensorial com as formas da natureza, o que denota uma concepção externalista. 
Entretanto, pode-se (com Heidegger) localizar no mesmo filósofo o início do processo de "esquecimento do Ser", a partir da ênfase atribuída à linguagem e aos raciocínios lógicos no Organon, o que se acentuou na escolástica medieval, em que a exegese do texto bíblico substituiu a experiência natural como método de investigação da verdade, conduzindo ao que Heidegger chamou de "Onto-Teo-Logia".

A ciência moderna, por sua vez, se erigiu sobre o princípio filosófico de distinção entre qualidades primárias, que seriam objetivas e estudadas pela física, e as qualidades secundárias, que seriam subjetivas, não abordáveis pela física. Neste modelo, as experiências subjetivas qualitativas independem de uma efetiva interação com as formas da natureza; em Kant, por exemplo, na Crítica da Razão Pura, os fenômenos são considerados como sendo constituídos pela junção da "matéria" sensível (cujas qualidades intrínsecas são consideradas relevantes) e por formas qualitativas apriori.

$\mathrm{Na}$ visão internalista de Descartes, poderíamos ter experiências qualitativas sem interação com as formas da natureza, como seria o caso dos sonhos. Já para o empirismo de Hume, as impressões que temos nos sonhos seriam "mais fracas" que as impressões que temos quando interagimos diretamente com as formas da natureza, o que sugere uma abordagem externalista dos conteúdos da experiência consciente.

\section{GOETHE, HEIDEGGER E A "CEGUEIRA BOTÂNICA"}

A abordagem de Goethe pode ser considerada como um ponto de retorno ao externalismo aristotélico, nas ciências e filosofia da natureza. Para Goethe, as ciências da natureza se iniciam por meio de uma interação direta entre o pesquisador e as formas da natureza; ou seja, pela presença destas formas, e não por sua representação. A natureza deve se manifestar nos resultados da pesquisa científica: "O modo de ciência de Goethe, entendido como uma fenomenologia da natureza, pode ser um meio valioso para promover essa abertura para a presença viva do mundo natural, incluindo seus animais, mas também suas plantas, suas formas terrestres, suas regiões ecológicas, suas formações de terra, céu e água. Sua presença sensual se expressa, por exemplo, através da luz, da escuridão e da cor" (Seamon, 2005, p. 86; tradução de APJ).

Segundo Seamon, a definição de fenomenologia de Heidegger se aproxima do conceito de ciência de Goethe: "Deixar aquilo que se mostra ser visto em si mesmo no próprio modo em que se mostra de si mesmo" (Seamon, 2005). O problema do "esquecimento do Ser", formulado 
por Heidegger, e por ele atribuído à crescente valorização da técnica na cultura humana, pode então ser aproximado ao problema da "cegueira botânica". Conforme Salatino e Buckeridge (2016, p. 178), "parece ser uma característica da espécie humana perceber e reconhecer animais na natureza, mas ignorar a presença de plantas...Nós interpretamos as plantas como elementos estáticos, compondo um plano de fundo, um cenário, diante do qual se movem os animais". A "cegueira botânica" se caracteriza por três atitudes: "a) a incapacidade de reconhecer a importância das plantas na biosfera e no nosso cotidiano; b) a dificuldade em perceber os aspectos estéticos e biológicos exclusivos das plantas; c) achar que as plantas são seres inferiores aos animais, portanto, imerecedores de atenção equivalente" (Salatino e Buckeridge, 2016, p. 178).

Heidegger, como é bem conhecido, mantinha uma interação estreita com a floresta; um dos seus livros (sobre história da filosofia) se chamou "Caminhos da Floresta". Entretanto, a efetiva manifestação do Ser como fenômeno temporal seria dependente da linguagem; não a linguagem da tecno-ciência, comprometida com a representação das 'qualidades primárias' e distanciada das qualidades subjetivas, mas a linguagem poética.

Heidegger analisou o "esquecimento do Ser" e as marcas da abordagem "onto-teológica" no trabalho dos principais filósofos ocidentais, mas é na sua discussão do "Princípio da Razão" de Leibniz que ele utiliza um exemplo propriamente botânico: o perfume de uma rosa (Heidegger, 1962). Segundo Heidegger, as explicações causais deste fenômeno não conseguem captar o que lhe é próprio, ou seja, a qualidade subjetiva que se manifesta no plano fenomenológico da efetiva interação com a flor.

Heidegger supõe uma incompatibilidade entre o Ser e a Cultura/Técnica, mas em um perspectiva evolutiva pode-se argumentar pela sua continuidade. Todos os sistemas vivos derivam de uma mesma origem, compondo uma "árvore da vida". Plantas e animais estão no mesmo patamar evolutivo, com diferentes especializações anátomo-fisiológicocomportamentais. As plantas apresentam atividades, em seu tecido contínuo (sincício), que correspondem à cognição e sentiência (entendida como a capacidade de sentir). Além destas atividades, a evolução dos animais desenvolveu o pensamento e a inteligência, que correspondem às atividades da rede neuronal.

No Monismo de Triplo Aspecto (MTA; Pereira Jr., 2013, 2016) a consciência é concebida como sendo um veículo para a atualização de formas naturais, que de outra forma permaneceriam em um estado potencial e, portanto, sem influência nas vias evolutivas. A 
cultura e tecnologia humanas, a aplicação do conhecimento à transformação da natureza, seriam processos completamente naturais de desdobramento das potencialidades de uma fonte única de Ser. Na evolução da vida terrestre, as plantas constituem o alimento e o ambiente necessários para a vida animal; nossos sentidos evoluíram em interação com as formas da natureza, sendo que muitos deles (sabores, cores) co-evoluiram com as formas das plantas.

$\mathrm{Na}$ entrevista em forma de debate concedida ao Grupo de Filosofia Temática (transcrita neste volume da Revista Complexitas), também discutimos a continuidade ou descontinuidade entre as formas de vida, e entre a Natureza e a Cultura/Técnica.

\section{EVOLUÇÃO HUMANA}

Como foi possível para a espécie humana passar da onipresença da natureza para uma cultura em que predomina a representação da natureza? Na evolução humana, a partir dos primeiros hominídeos, como o Australopitecus (3,6 milhões de anos), surgiram o Homo Habilis (2 m.a.) e o Neandertal (300 a 29 mil anos); do Habilis, surge o Homo Sapiens, a atual configuração de nossa espécie. Enquanto o Neandertal foi extinto, o Habilis provavelmente assegurou sua sobrevivência em ambientes hostis por meio do uso de ferramentas de pedra, ossos e madeira, o que teve também um efeito colateral importante: a emergência da linguagem verbal.

Segundo a hipótese de Greenfield (1991), as áreas motoras corticais responsáveis pelo movimento voluntário das mãos no manuseio das ferramentas, pelo Homo Habilis, seriam precursoras da Área de Broca, que é responsável pelo controle dos músculos vocais e também pela construção gramatical. Enquanto os demais primatas realizam vocalizações involuntárias, controladas por um circuito subcortical (conhecida como área periaquedutal cinza), os primeiros Homo Sapiens passaram a dispor da capacidade de realizar vocalizações complexamente articuladas, a partir de uma mutação que conectou o córtex motor com os músculos responsáveis pelos movimentos de nosso sistema fonador, que, aliás, é o sistema muscular mais complexo do corpo humano.

O cérebro humano evoluiu, ao longo de milhões de anos, para uma estrutura conhecida como "Cérebro Triuno" (MacLean, 1990). Esta estrutura é composta por três camadas, sendo a primeira relativa ao "cérebro reptiliano", restrito a reflexos elementares, como a busca por alimento, o ataque a presas ou fuga de predadores, e a reprodução. A segunda camada se compõe do "sistema límbico", que seria responsável por uma maior variedade de emoções, 
inclusive emoções elicitadas no contexto social, como o cuidado materno. A terceira camada corresponde ao "neocortex", aquela camada mais externa que caracteriza o cérebro dos primatas e cetáceos, e que é responsável pelos processamentos mais abstratos, como valores éticos e estéticos, pois lida com representações da realidade.

Na psicologia aplicada à economia, a distinção entre processamentos mentais irrefletidos e refletidos se tornou relevante, propiciando o Prêmio Nobel para um cientista cognitivo, Daniel Kahneman, em 2002. Este autor desenvolveu uma abordagem da mente humana na qual esta é concebida como composta de dois sistemas, o primeiro responsável, na maior parte do tempo, por nossas atitudes irrefletidas, e o segundo responsável pela pequena fração de decisões refletidas.

Na evolução humana, e principalmente a partir da modernidade, nossas relações com as plantas passaram para o plano irrefletido e automático (Sistema 1 de Kahneman), enquanto nossa atenção é focada no plano das representações da natureza (Sistema 2), no qual se desenrolam as relações econômico-políticas de mercado, na sociedade capitalista.

O problema não decorre da tecnologia, mas de nossa organização mental e social. O uso da linguagem verbal como mediadora das relações sociais e também das relações com a natureza levou a um "esquecimento do Ser" das plantas, ou seja, à menor presença de plantas na vida humana, em detrimento de representações verbais ou imagéticas, e manipulações artificiais de suas propriedades físico-químico-biológicas. Uma reflexão a respeito das várias dimensões deste processo se torna necessária, para distinguir entre os usos pertinentes e os usos não pertinentes, em relação à qualidade de vida humana. Não se trata de uma recusa a toda técnica ou tecnologia, mas de uma avaliação crítica e pragmática dos fatores favoráveis e desfavoráveis à interação homem-plantas.

\section{COMO O PROBLEMA SE APLICA AO BRASIL?}

Trazendo a discussão acima para o espaço e tempo da sociedade brasileira do século XXI, notamos que toda a economia brasileira está direta ou indiretamente relacionada com o cultivo de plantas; porém, devido a nosso status de colonizado, muitas vezes damos preferência ao consumo de plantas exóticas. Haveria muitas vantagens em se priorizar plantas nativas, como a exclusividade dos produtos, a facilidade do cultivo (sem agrotóxicos e adubos químicos), e desenvolvimento de tecnologias a partir do conhecimento dos povos nativos.

A produção de energia útil para as atividades humanas é um campo em que se pode 
repensar o papel das plantas. Estas convertem energia solar em energia química, que usamos em máquinas; recentemente, pesquisadores holandeses descobriram a possibilidade de utilização direta da energia elétrica das plantas, obtida da energia solar, sem necessidade da fase de energia química (vide https://www.youtube.com/watch?v=BqnDku5Z_W4). Um protótipo foi desenvolvido, no Brasil, por estudantes em Saquarema, estado do Rio de Janeiro (https://www.youtube.com/watch?v=iI9vurka6nQ\&t=57s). O método também poderia ser utilizado com árvores, levando à conjectura de que a energia do futuro seria gerada em bosques e florestas (https://www.youtube.com/watch?v=Ty6c1FHY77U), o que traz óbvias vantagens para a preservação ambiental e para a economia brasileira

\section{CONSIDERAÇÕES FINAIS}

Este pequeno ensaio termina com uma sugestão no sentido de que não seria possível para a sociedade humana usufruir de qualidade de vida sem haver uma interação direta com as plantas. No Brasil, precisamos conceber novas tecnologias que promovam maior proximidade com as plantas, ao invés de nos afastar delas; por exemplo, a robótica nos seria de pouco interesse, por gerar problemas sociais como o desemprego, enquanto um novo modelo de relação homem-planta poderia gerar muitas oportunidades de trabalho, por exemplo, em Ecovilas Auto-Sustentáveis, geridas por cooperativas de pequenos proprietários e produtores. A pesquisa em filosofia e ciência podem contribuir para este novo modelo, gerando os conhecimentos e tecnologias necessários para sua implementação.

Agradecimentos aos colegas Prof. Dr. Gustavo Maia Silva, pela discussão do tema e indicação de referencias bibliográficas, e ao Prof. Dr. Antônio Sérgio Nunes, pelo convite para participação na IV Jornada Benedito Nunes, na UFPA, onde este trabalho foi apresentado, e pela constituição do grupo interdisciplinar de trabalho, no projeto "Quintal Ecológico", que constitui uma modalidade de implementação das ideias aqui expostas. 


\section{REFERÊNCIAS BIBLIOGRÁFICAS}

GREENFIELD, P. 'Language, Tools, and Brain: The Ontogeny and Phylogeny of Hierarchically Organized Sequential Behavior'. Behavioral and Brain Sciences 14, p. 531-51, 1991.

HEIDEGGER, M. Le Principe de Raison. Trad. André Préau. Paris: Gallimard, 1962.

MCLEAN, P.D. The Triune Brain in Evolution. New York: Plenum Press, 1990.

PEREIRA Jr. A Triple-Aspect Monism: A Conceptual Framework for the Science of Human Consciousness. In A. Pereira Jr. \& D. Lehmann (Eds.) The Unity of Mind, Brain and World: Current Perspectives on a Science of Consciousness. Cambridge, UK: Cambridge University Press, p. 299337, 2013.
PEREIRA JR., A., ILARIO, E. BRESCIANI FILHO, E. Modelando o Monismo de Triplo Aspecto em um Espaço de Estados com Dimensões Fracionárias. Complexitas: Rev. Fil. Tem. v.1, n. 1, p. 78-100, jan.-jun. 2016. Disponível em: http://dx.doi.org/10.18542/complexitas.v1i 1.3411

SALATINO, A. \& BUCKERIDGE, M. "Mas de que te serve saber botânica?". Estudos Avançados, v.30, n.87, p. 177196, 2016. Disponível em: https://dx.doi.org/10.1590/S010340142016.30870011

SEAMON, D. Goethe's Way of Science as a Phenomenology of Nature. Janus Head, v.8, n.1, p.86-101, 2005. Disponível em: http://www.janushead.org/81/Seamon.pdf? $\mathrm{q}=$ goethes

JUNIOR, A.P. As Plantas e a Qualidade de Vida Humana. Complexitas - Rev. Fil. Tem. Belém, v. 2, n. 2, p. 34-42, jul./dec. 2017. Disponível em:< http://www.periodicos.ufpa.br/index.php/complexitas/article/view/6596>. Acesso em: 07 de julho de 2019. 